Internat. J. Math. \& Math. Sci.

Vol. 23, No. 3 (2000) 223-224

S0161171200003446

(C) Hindawi Publishing Corp.

\title{
A NOTE ON COMMUTATIVITY OF NONASSOCIATIVE RINGS
}

\section{S. S. KHAN}

(Received 31 December 1998 and in revised form 16 May 1999)

ABSTRACT. A theorem on commutativity of nonassociate ring is given.

Keywords and phrases. Rings with unity, commutativity of rings, nonassociative rings.

2000 Mathematics Subject Classification. Primary 17A30; Secondary 16Y30.

In 1968, Johnsen, Outcalt, and Yaqub [3] have established that a nonassociative ring $R$ with identity 1 satisfying the relation $(x y)^{2}=x^{2} y^{2}$ for every $x$ and $y$ in $R$, is commutative. Gupta [2] has shown that if $R$ is a nonassociative 2-torsion free ring with unity 1 satisfying $(x y)^{2}=(y x)^{2}$ for all $x, y$ in $R$, then $R$ is commutative. Later, Yuanchun [4] proved that a Baer-semisimple ring $R$ is commutative if and only if $(x y)^{2}-x y^{2} x$ is central. The existence of noncommutative ring $R$ with $R^{2} \subseteq Z(R)$, center of $R$, rules out the possibility that $(x y)^{2}-x y^{2} x \in Z(R)$ might yield commutativity even in associative rings. As an example, consider $A_{3}=\left\{\left(a_{i j}\right) / a_{i j}\right.$ are integers with $\left.a_{i j}=0, i \geq j\right\}$. Then $A_{3}$ is a noncommutative nilpotent ring of index 3 in which $(x y)^{2}-x y^{2} x$ is central for all $x, y$ in $A_{3}$.

This naturally gives rise to the following question: what additional conditions are needed to insure the commutativity of $R$ when $R$ is an arbitrary ring? With this motivation, Ashraf, Quadri, and Zelinsky [1] established the following result.

THEOREM 1. Let $R$ be an associative ring with unity 1 satisfying $(x y)^{2}=y x^{2} y$ for all $x, y$ in $R$, then $R$ is commutative.

They used very complicated combinatorial arguments. In this connection we prove the following results.

THEOREM 2. Let $R$ be a nonassociative ring with unity 1 satisfying $(x y)^{2}=\left(x y^{2}\right) x$ for all $x, y$ in $R$. Then $R$ is commutative.

Proof. Replacing $y+1$ for $y$ in $(x y)^{2}=\left(x y^{2}\right) x$, we obtain

$$
(x(y+1))^{2}=\left(x(y+1)^{2}\right) x, \text { which yields } x(x y)=(x y) x .
$$

Repeating this argument for $x+1$ in place of $x$, equation (1) gives

$$
x(x y)+x y=(x y) x+y x .
$$

Thus equation (2) together with equation (1), shows that $R$ is commutative.

Similarly, we can prove the following theorem. 
THEOREM 3. Let $R$ be a nonassociative ring with unity 1 satisfying $(x y)^{2}=\left(y x^{2}\right) y$ for all $x, y$ in $R$. Then $R$ is commutative.

If we drop the restriction of unity 1 in the hypothesis, $R$ may be badly noncommutative.

EXAMPLE. Let

$$
R=\left\{\alpha I+B \mid I=\left(\begin{array}{ccc}
1 & 0 & 0 \\
0 & 1 & 0 \\
0 & 0 & 1
\end{array}\right), B=\left(\begin{array}{ccc}
0 & \beta & \gamma \\
0 & 0 & \delta \\
0 & 0 & 0
\end{array}\right), \alpha, \beta, \gamma, \delta \in Z_{p}\right\},
$$

$p$ is a prime such that $p / n$ if $n$ odd or $2 p / n$ if $n$ even, and $Z_{p}$ is the ring of integers modulo $p$. Then $B^{3}=0$, for $n \geq 3$ and

$$
(\alpha I+B)^{n}=\alpha^{n} I+n \alpha^{n-1} B+\frac{n(n-1)}{2 !} \alpha^{n-2} B^{2}+\cdots=\alpha^{n} I,
$$

because $n=0$ and $n(n-1) / 2 !=0$ in $Z_{p}$, where $p / n$ and $2 p / n(n-1)$.

However, $R$ need not be commutative.

ACKNOWLEDGEMENT. The author is thankful to the learned referee for the useful comments.

\section{REFERENCES}

[1] M. Ashraf, M. A. Quadri, and D. Zelinsky, Some polynomial identities that imply commutativity for rings, Amer. Math. Monthly 95 (1988), no. 4, 336-339. MR 89c:16045. Zbl 643.16021.

[2] R. N. Gupta, A note on commutativity of rings, Math. Student 39 (1971), 184-186. MR 48 6192. Zbl 271.17003.

[3] E. C. Johnsen, D. L. Outcalt, and A. Yaqub, An elementary commutativity theorem for rings, Amer. Math. Monthly 75 (1968), 288-289. MR 37\#1417. Zbl 162.33602.

[4] G. Yuanchun, Some commutativity theorems of rings, Acta Sci. Natur. Univ. Jilin 3 (1983), $11-18$.

KHAN: DePARTMENT OF MATHEMATICS AND COMPUTER SCIENCE UNIVERSITY OF Leicester, LEICESTER, LE1 7RH, ENGLAND, UK 


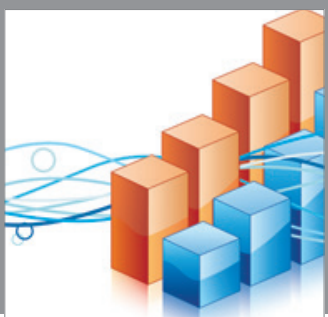

Advances in

Operations Research

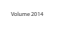

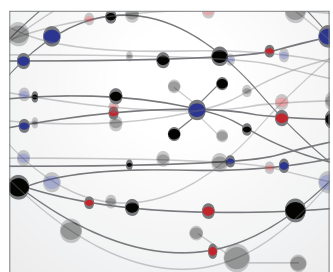

\section{The Scientific} World Journal
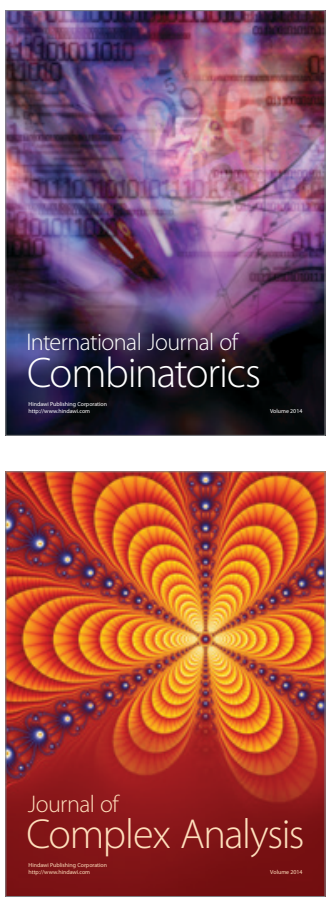

International Journal of

Mathematics and

Mathematical

Sciences
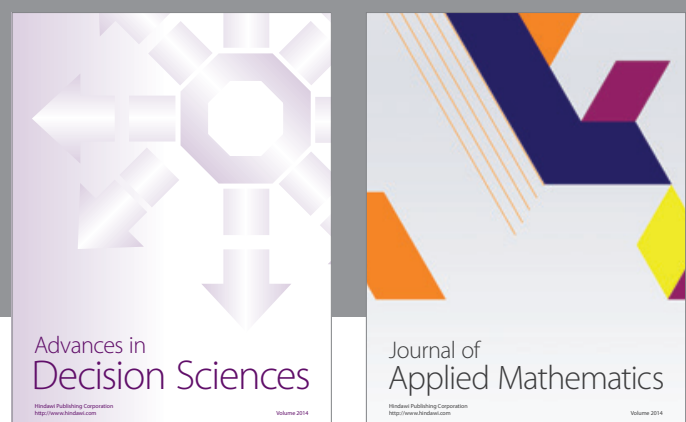

Journal of

Applied Mathematics
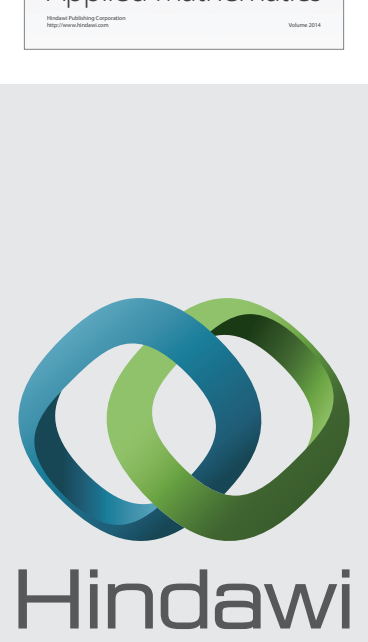

Submit your manuscripts at http://www.hindawi.com
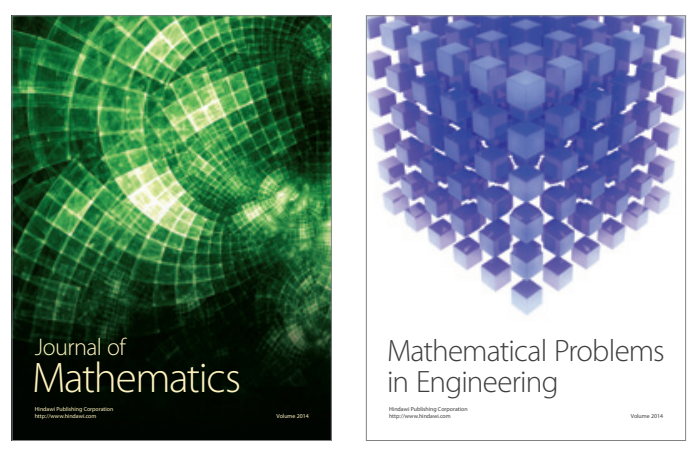

Mathematical Problems in Engineering
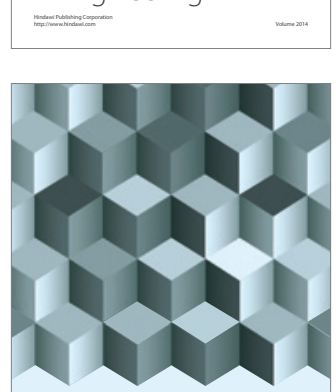

Journal of

Function Spaces
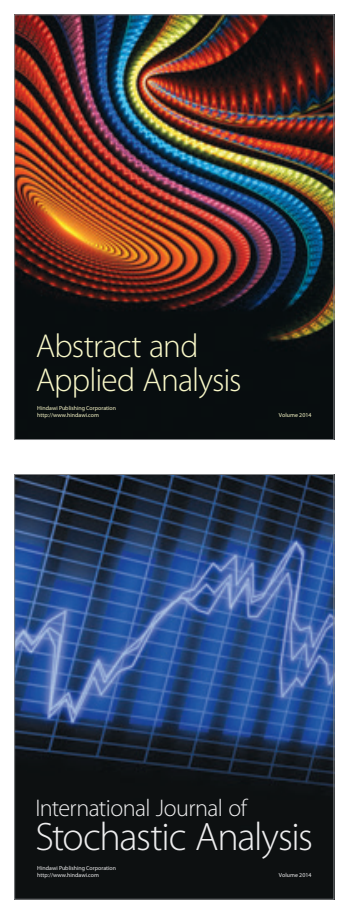

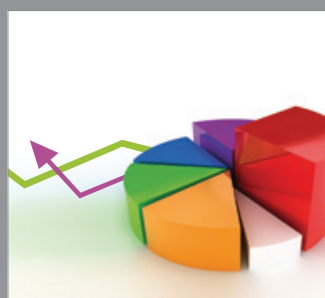

ournal of

Probability and Statistics

Promensencen
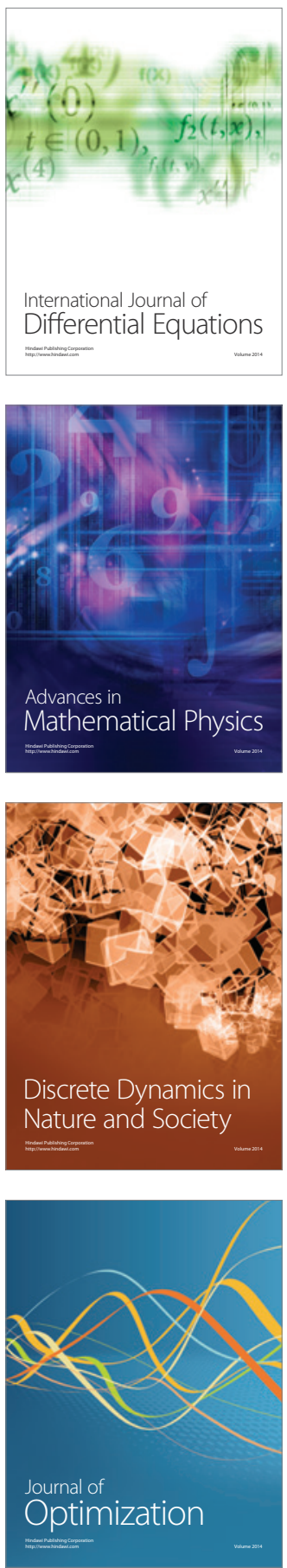